\title{
As consequências paradoxais do trabalho intensificado: um estudo com gestores de logística
}

\section{The paradoxical consequences of intensified work: a study with logistic managers}

\author{
Ariane Serpeloni Tavares (orcid.org/0000-0001-9604-6844)' \\ Rosemeire Aparecida Scopinho (orcid.org/0000-0002-2771-4770)2
}

\begin{abstract}
Resumo
O artigo aborda os resultados de uma pesquisa qualitativa sobre as consequências do trabalho intensificado para dez gestores do setor de logística de transportes. O trabalho se torna intensificado pelo emprego de diversos mecanismos, especialmente aqueles que conduzem ao aumento do ritmo de execução das atividades ou da jornada de trabalho. As principais consequências do trabalho intensificado identificadas mostraram-se paradoxais, já que, se por um lado, os gestores apontaram efeitos negativos (impactos na saúde, dificuldades de conciliação da vida privada com as demandas laborais e diluição das barreiras entre tempo de trabalho e não trabalho), por outro lado, indicaram algumas vantagens, como o gosto pelo ritmo elevado e os benefícios financeiros e de carreira decorrentes da aceitação de condições de trabalho intensificadas. A influência da ideologia gerencialista foi considerada na compreensão e ponderação sobre esses benefícios do trabalho intensificado.
\end{abstract}

Palavras-chave: Trabalho intensificado. Trabalho imaterial. Gestores. Saúde. Ideologia gerencialista.

\begin{abstract}
The article addresses the results of a qualitative research on the consequences of intensified work for ten managers in the transport logistics sector. The work becomes intensified by the use of several mechanisms, especially those that lead to an increase in the rate of execution of activities or work hours. The main consequences of the intensified work identified proved to paradoxical, since, on the one hand, the managers pointed out negative effects (health impacts, difficulties in reconciling private life with work demands and diluting of barriers between working time and non-work), on the other hand, indicated some advantages, such as the preference for the high rate and the financial and career benefits resulting from the acceptance of intensified working conditions. The influence of managerial ideology was considered in the understanding and weighting about these benefits of intensified work.
\end{abstract}

\footnotetext{
${ }^{1}$ Universidade Federal de São Carlos, São Carlos, Brasil. E-mail: ariserpeloni82@yahoo.com.br..

${ }^{2}$ Universidade Federal de São Carlos, São Carlos, Brasil. E-mail: scopinho@ufscar.br.
} 
Keywords: Intensified work Immaterial work. Managers. Health. Managerialist ideology.

O trabalho está entre as principais atividades humanas e tem papel fundamental para a construção da identidade, para a socialização, para a aprendizagem, para a sobrevivência e para a ocupação do tempo. A importância do trabalho se dá tanto na esfera econômica quanto na esfera psíquica, enquanto fonte de identificação e desenvolvimento de potencialidades, ou ainda, de sofrimento e de adoecimento (Navarro \& Padilha, 2007). Na contemporaneidade, a relação do trabalhador com sua atividade laboral tem sido marcada pela precariedade, que engloba a intensificação laboral e a flexibilização das relações de trabalho (Lima, Barros, \& Aquino, 2012). A intensificação laboral presenciada nos dias de hoje insere-se no contexto das mudanças econômicas, sociais, políticas e ideológicas que levaram à crise do capitalismo na década de 1970 e suas repercussões para a organização do trabalho (Dal Rosso, 2008).

Intensificar o trabalho, segundo Dal Rosso (2008), consiste em incorporar mais encargos e tarefas às rotinas dos trabalhadores para reduzir os tempos mortos da jornada, o que pode ocorrer por meio de diversos mecanismos, tais como as mudanças tecnológicas e organizacionais, que demandam dos trabalhadores um maior dispêndio de suas energias físicas, cognitivas e emocionais. Conforme Green (2004), a intensificação do trabalho não consiste apenas na elevação da carga horária trabalhada, mas também em um aumento na proporção de horas de efetivo trabalho produtivo para cada hora da jornada de trabalho. Ou seja, há elevação do esforço extensivo e do esforço intensivo: o primeiro consiste no tempo despendido no trabalho, enquanto o segundo corresponde à intensidade que o trabalho tem durante as horas trabalhadas.

Neste artigo, abordamos o trabalho intensificado vivenciado por trabalhadores do setor de transportes, que ocupam cargo gerencial e que, apesar de sua posição privilegiada na estrutura social, não estão imunes à precariedade laboral. $O$ trabalho do gestor caracteriza-se por jornadas longas e sem limites bem definidos (Máximo, Araújo, \& Zambroni-de-Souza, 2014; Scanfone, Carvalho Neto, \& Tanure, 2008), uso constante de tecnologias móveis de comunicação (Borges \& Joia, 2013; Cavazotte, Lemos, \& Brollo, 2014) 
e um cotidiano repleto de imprevistos, de interrupções da rotina e de replanejamentos (Almeida \& Merlo, 2008; Davel \& Melo, 2005; Leite \& Paiva, 2009). Dado que o trabalho gerencial consiste em desenvolver atividades de planejamento, organização e acompanhamento do trabalho executado pelos subordinados, para que se atinjam os objetivos do departamento e, consequentemente, da empresa (Davel \& Melo, 2005), podemos considerar que eles realizam um trabalho de caráter imaterial, no qual as cargas afetiva e cognitiva se destacam e, portanto, as características e consequências da intensificação do trabalho podem se diferenciar das encontradas em atividades de caráter material, conforme foi apontado por Dal Rosso (2006).

Entendemos que o trabalho gerencial pode se caracterizar como uma atividade laboral imaterial que, diante das transformações tecnológicas e organizacionais do nosso tempo, tem também se tornado, cada vez mais, intensificada. Nesse sentido, estudar os gestores' faz-se importante diante das poucas pesquisas que se dedicam a esse tipo de trabalhador utilizando os conceitos de trabalho intensificado e trabalho imaterial e que focalizam a precariedade das suas condições de trabalhoii.

Ademais, os estudos localizados na literatura, que envolvem gestores, abordam outros setores da economia, especialmente o bancário (Máximo et al., 2014; Nascimento, Duarte, \& Mendes, 2012; Oltramari, Grisci, \& Weber, 2011; Silva \& Rosseto, 2010) e nenhuma pesquisa nacional com gestores do setor de transportes foi encontrada na literatura consultadaiii. Diferenças na intensidade dos mais diversos setores econômicos foram identificadas por Dal Rosso (2008), que apontou o setor de transportes entre os mais intensificados. O transporte é a área operacional da logística que, geograficamente, movimenta e posiciona os estoques de uma empresa na forma de matérias-primas para a produção e de produtos acabados ou não. A área de logística, dentro da qual está inserido o setor de transportes, atua 24 horas por dia e tem como objetivo ter o produto certo, na quantidade certa, na hora certa, no lugar certo e pelo menor custo possível (Fleury, Wanke, \& Figueiredo, 2000). Depreende-se disso que o cumprimento desse objetivo pode exigir um trabalho em ritmo acelerado, com acompanhamento e atendimento das demandas e emergências que podem ocorrer a qualquer hora do dia. Assim, consideramos que esse setor tem peculiaridades que podem levar à elevada intensidade do trabalho dos gestores, 
em especial, a ininterrupção das operações de transporte e a necessidade de atender os prazos de entrega, o que the confere relevância como lócus de estudo do trabalho intensificado.

Apesar de o processo de intensificação do trabalho trazer ganhos de produtividade para as empresas, já que mais trabalho é produzido no mesmo período de tempo ou com a mesma quantidade de trabalhadores, ele também pode trazer impactos negativos para estes, dentre os quais podemos destacar, especificamente entre gerentes, os problemas de saúde e a interferência demasiada do trabalho na vida privada (Almeida \& Merlo, 2008; Máximo et al., 2014; Nascimento et al., 2012; Oltramari et al., 2011; Silva \& Rosseto, 2010). Embora a literatura identifique consequências nocivas decorrentes do trabalho intensificado, outras pesquisas apontam para fatores de manutenção dos trabalhadores sob essas condições, tais como o sentimento de recompensa pelos desafios, aprendizado, oportunidades de carreira, status e salários recebidos em contrapartida, além do medo e da insegurança com relação ao futuro (Burke \& Fiksenbaum, 2008; Lemos, Gottlieb, \& Costa, 2016; Neves, Lemos, \& Costa, 2014).

Com o intuito de entender o processo saúde-doença-trabalho dos entrevistados, utilizamos o conceito de desgaste (Laurell \& Noriega, 1989), entendido como a perda da capacidade potencial e/ou efetiva corporal e psíquica, que não necessariamente é irreversível, mas que pode se expressar como doença. Os processos de desgaste são multideterminados e decorrem da necessidade de adaptação do corpo às condições ambientais, entendidas como sínteses das formas sociais de organização do trabalho e não como condições naturais. Essa abordagem utiliza o conceito de cargas de trabalho ao invés do conceito de riscos e considera que as cargas consistem nas condições do ambiente e da organização do trabalho que interatuam dinamicamente entre si e com o corpo do trabalhador, gerando os processos de adaptação e desgaste.

Diante do exposto, o presente artigo tem como foco discutir as consequências da vivência de condições de trabalho intensificadas para gestores do setor de logística de transportes de diferentes empresas, identificadas por meio de uma pesquisa de caráter qualitativo. 


\section{Método}

Foram selecionados como participantes da pesquisa dez trabalhadores que ocupavam cargos de liderança intermediária (coordenadores e gerentes), ou seja, trabalhadores que possuíam função de gestão de uma área da empresa e tinham subordinados diretos. Esses trabalhadores estavam empregados em empresas privadas, de grande porte, do ramo de logística, ou atuavam na área de transportes de empresas de outros segmentos. O gestor na área de logística de transportes é responsável, em síntese, por garantir que as operações de armazenagem, carregamento, transporte e entrega de mercadorias e insumos sejam realizadas de forma eficaz, com o menor custo e a melhor qualidade possíveis (Fleury et al., 2000). Para tanto, deve gerenciar as equipes que executam essas atividades, controlar indicadores de produtividade e custos, lidar com clientes, fornecedores e colaboradores de outras áreas da empresa.

O parâmetro para inclusão dos entrevistados na pesquisa, além dos já citados, incluiu a necessidade de que tivessem vivenciado condições de trabalho intensificadas, como as elencadas por Burke e Fiksenbaum (2008): a) trabalhos com prazos apertados; b) atividades com escopos imprevisíveis; c) responsabilidades relacionadas a mais de uma função; d) necessidade de atender eventos de trabalho fora do horário regular; e) disponibilidade 24 horas por dia; f) responsabilidade por lucros e prejuízos; g) viagens em grande volume; h) presença física no local de trabalho por período superior a dez horas por dia; i) responsabilidade por recrutar e formar pessoas; j) ter um grande número de subordinados diretos. Não era necessário que todos esses requisitos estivessem presentes em conjunto.

Os dados foram coletados por meio de entrevistas semiestruturadas com os gestores, nas quais se utilizou um roteiro contextual que contemplava tópicos, como: dados sociodemográficos; trajetória profissional; rotina de trabalho; responsabilidades; carga de trabalho; consequências do trabalho; aspectos organizacionais; reflexões sobre o trabalho intensificado. As informações fornecidas pelos sujeitos não se referiram apenas ao trabalho que realizavam na época da entrevista, mas a toda a sua vivência profissional, em especial naqueles empregos em que o trabalho era mais intenso na perspectiva do trabalhador. $O$ 
conteúdo foi gravado, com consentimento dos entrevistados, e, posteriormente, transcrito.

As entrevistas tiveram duração média de uma hora e 15 minutos e foram realizadas, em sua maioria, fora do ambiente e horário de trabalho dos gestores. Utilizamos, como meio para a realização das entrevistas, chamadas de vídeo do Skype (software que permite a realização de chamadas entre dispositivos), que se mostrou um recurso fundamental para a condução da pesquisa, visto que facilitou o acesso aos entrevistados em várias localidades (Rio Grande do Sul, Santa Catarina, Paraná, São Paulo e Minas Gerais), reduziu os custos de pesquisa, permitiu maior flexibilidade no agendamento de horários e evitou problemas que decorreriam das remarcações e cancelamentos que, muitas vezes, ocorreram próximo do horário agendado.

O acesso aos gestores foi realizado por meio da abordagem direta aos possíveis entrevistados, que já faziam parte da rede de contatos da pesquisadora ou que foram indicados pelos próprios entrevistados. Esse tipo de procedimento amostral que utiliza cadeia de referências é denominado de snowball sampling (amostragem em bola de neve) e consiste, segundo Vinuto (2014), em um processo de permanente coleta de informações que procura tirar proveito das redes de relacionamentos dos entrevistados, formando um conjunto cada vez maior de contatos potenciais. A quantidade de sujeitos entrevistados foi determinada pelo critério de saturação, em que o número de participantes é definido a partir das necessidades do processo de conhecimento, tendo-se como mais relevante do que a quantidade a existência de vinculação significativa dos sujeitos com o problema a ser investigado (Deslandes, 2009). Quanto a esse requisito, acreditamos que a escolha dos sujeitos ocorreu de forma adequada, visto que selecionamos, intencionalmente, apenas trabalhadores que tenham vivenciado o trabalho intensificado, ou seja, a descrição das condições de trabalho, durante as entrevistas, atendeu aos critérios elencados para definir um trabalho intensificado.

Os dados foram processados por meio da Análise de Conteúdo Temática, para identificar os núcleos de sentido que compõem a comunicação, seguindo a proposta de Gomes (2009): leitura compreensiva e exaustiva do conteúdo, exploração do material (análise propriamente dita) e elaboração da síntese interpretativa. Os núcleos de sentido identificados foram: o trabalho do gestor de transportes, as características do trabalho 
intensificado e as consequências das suas condições laborais.

A pesquisa foi aprovada pelo Comitê de Ética em Pesquisas com Seres Humanos, inclusive, quanto à inexigibilidade de autorização das empresas que empregavam os entrevistados, e atendeu rigorosamente à Resolução $n^{\circ}$ 466/2012 do Conselho Nacional de Ética em Pesquisa (Brasil, 2012).

Os dez entrevistados - sete gerentes e três coordenadores - eram todos do sexo masculino, tinham entre 27 e 46 anos de idade e entre cinco e 23 anos de experiência na área de transportes. Metade era pós-graduada e apenas um dos coordenadores ainda estava cursando o ensino superior na época das entrevistas. Oito entrevistados eram casados, um divorciado e um solteiro. Sete deles tinham filhos. Trabalhavam em empresas privadas de grande porte, predominantemente sociedades anônimas de capital fechado.

Os principais resultados encontrados na pesquisa serão apresentados nas seções a seguir, organizados conforme os núcleos de sentido identificados.

\section{"Eu faço, basicamente, tudo": o trabalho do gestor de logística de transportes}

A função gerencial (seja gerente ou coordenador), de acordo com os entrevistados, envolve uma gama de atividades e tem como objetivo garantir que a unidade que gerenciam funcione corretamente e dê os resultados esperados pela empresa. No setor de transportes, isso compreende a gestão de todas as áreas relacionadas à operação sob sua responsabilidade: a) pessoas (contratação, desenvolvimento, ações motivacionais, desligamentos, ajustes de quadro, saúde e segurança); b) ativos operacionais (manutenção e disponibilidade de frota, insumos, ferramentas, equipamentos); c) financeiro (planejamento orçamentário, controle e aprovação de custos, alocação de investimentos, faturamento), d) operação (definição e acompanhamento dos processos de trabalho); e) clientes (relacionamento, visitas, atendimento de demandas). Mostrou-se marcante na atividade gerencial o constante contato com pessoas - clientes, pares e subordinados - e com informações que são provenientes de reuniões, telefonemas, mensagens, e-mails, sistemas de gestão, etc. Essas características, portanto, levam-nos a compreender que a atividade gerencial é, predominantemente, imaterial, já que envolve a realização de tarefas de caráter 
intelectual, analítico, simbólico, criativo, comunicativo e afetivo (Grisci, 2011; Hardt \& Negri, 2001).

\section{"É bem puxado, não tem pausa": caracterização do trabalho intensificado dos gestores}

Antes de apresentar quais foram as consequências do trabalho gerencial intensificado apontadas pelos entrevistados, cabe dedicarmos um espaço para descrever as condições de trabalho vivenciadas pelos gestores e que indicam que o trabalho deles pode ser caracterizado como intensificado. Consideramos que o trabalho se torna intensificado pelo emprego de técnicas de intensificação pelas empresas, dentre as quais podemos citar: prolongamento e/ou flexibilização das jornadas; elevação do ritmo e da velocidade de execução das atividades; exigência de polivalência, flexibilidade e versatilidade dos trabalhadores; gestão por resultados; adoção de inovações tecnológicas como os smartphones e celulares corporativos (Dal Rosso, 2008). Ademais, consideramos que um trabalho é intensificado quando estão presentes características, como: alto ritmo, altas jornadas, disponibilidade fora do horário de trabalho, viagens constantes, dentre outras (Burke \& Fiksenbaum, 2008). Todas essas características foram evidenciadas pelos entrevistados, sendo que, para cada um deles, alguns desses elementos destacavam-se em relação a outros.

Levando em consideração a definição de Green (2004), uma das características de um trabalho intensificado é o alto esforço extensivo, que pode ser evidenciado pela elevada jornada e seu prolongamento para além da presença física na empresa. Com relação à jornada, os entrevistados informaram permanecer, em média, 12 horas por dia na empresa, mas também relataram picos de jornada que chegaram a 72 horas de trabalho, com pequenos períodos de descanso, dentro da própria empresa. A quantidade média de horas de trabalho apontadas pelos entrevistados se aproxima do que foi encontrado na pesquisa de Scanfone, Carvalho Neto e Tanure (2008), na qual os autores identificaram que 53\% dos executivos trabalhavam entre 10 e 11 horas por dia e 29\% trabalhavam 12 horas ou mais.

A carga horária relatada pelos gestores entrevistados, entretanto, foi subestimada pela não contabilização do tempo de disponibilidade para o trabalho, que ultrapassava as 
barreiras físicas da empresa, especialmente entre aqueles que eram responsáveis por operações ininterruptas. De acordo com o relato dos gestores, a extensão da jornada para outros locais era possibilitada, principalmente, pelo uso de tecnologias de comunicação, cuja onipresença foi expressa pelos entrevistados. Eles destacaram a necessidade de estarem disponíveis 24 horas por dia, seja para receber e responder a ligações, e-mails e mensagens instantâneas, o que nos leva a considerar que o uso dos dispositivos de comunicação é um elemento primordial na intensificação do trabalho dos gestores. A outra característica dos trabalhos intensificados, segundo Green (2004), é o elevado ritmo de trabalho, ou o esforço intensivo, que também foi identificado no dia a dia dos gestores. As entrevistas sinalizaram a existência de um elevado ritmo de trabalho, escopos imprevisíveis, diversidade de atividades, prazos apertados, excesso de demandas e a necessidade de flexibilidade por parte dos gestores para atendê-las.

Podemos entender, portanto, que os gestores têm que ter disponibilidade integral para o trabalho, serem polivalentes, realizar atividades variadas, muitas vezes ao mesmo tempo, e não conseguem, durante o horário normal de trabalho, realizar todas as atividades necessárias, o que leva, muitas vezes, ao prolongamento da jornada, dentro e fora da empresa. Todas essas características são consideradas como elementos de um trabalho intensificado, segundo Dal Rosso (2008) e Burke e Fiksenbaum (2008). Ademais, temos que apontar que oito dos dez gestores entrevistados informaram que estavam ou já estiveram inseridos em programas de remuneração variável e gestão por metas, o que foi apontado pelos entrevistados, bem como pela literatura (Dal Rosso, 2008; Pina, 2012), como um fator muito relevante para a intensificação laboral.

Consideramos que as características do trabalho intensificado apontadas pelos gestores relacionam-se, em grande parte, às particularidades do setor de transportes, que é definido pelos entrevistados como uma área "dinâmica", "imprevisível" e com "um ritmo diferente". Eles ainda a descreveram como "[u]ma indústria a céu aberto" que "não para", com "caminhoneiro rodando 24 horas, 365 dias por ano" o que demanda que o gestor fique "com a cabeça ligada o tempo todo". As pressões que incidem sobre os prazos de entrega das mercadorias, a imprevisibilidade dos trajetos e o caráter contínuo das operações de transporte demandam um ritmo de trabalho acelerado, bem como a extensão da jornada, 
dentro e fora da empresa.

\section{"Atrapalha muito esse negócio de logística": as consequências negativas do trabalho intensificado na percepção dos gestores}

Partindo para a análise das consequências do trabalho intensificado para os gestores entrevistados, elencamos como principais repercussões: a) impactos na saúde; b) dificuldades de conciliação da vida privada com as demandas do trabalho; c) diluição das barreiras entre tempo de trabalho e não trabalho (continuidade das preocupações e invasão do trabalho na vida privada), que serão apresentadas nas subseções a seguir.

\section{Impactos do trabalho na saúde}

Com relação aos impactos na saúde, alguns entrevistados relataram problemas de saúde mais graves, outros apresentaram alguns distúrbios ou dificuldades que podem resultar em doenças e, ainda, poucos deles não tiveram problemas de saúde específicos, ou, conforme a abordagem da Medicina Social Latino Americana (Laurell \& Noriega, 1989), houve desgaste, mas este não culminou em uma doença específica. O caso de Joséiv é ilustrativo do desgaste provocado pelo trabalho intensificado. Esse entrevistado demitiu-se do emprego anterior ao que ele tinha no momento da entrevista, em decorrência dos problemas de saúde que enfrentava. José contou que estava com 29 anos de idade e, na época, era o gerente responsável por uma unidade na qual trabalhavam mais de 700 pessoas. Era uma operação que demandava um trabalho extremamente intensificado e que o levou a ter problemas de saúde, como obesidade, pressão alta e problemas musculares, além de um desgaste generalizado:

Então, aí, com 29 anos, comecei a sentir que eu comecei a ter pressão alta ... Eu não dormia mais. Aí o telefone tocava de madrugada ... Não conseguia mais descansar naquele momento da vida... Eu estava com uma obesidade grande ... Aí um dia eu fui pegar minha filha, pequenininha, no colo, travei, travei minha coluna .... Nossa, fiquei muito mal de lá. Aí fui cuidar da minha saúde. Naquele momento, fui na nutricionista 
pela primeira vez, aí perdi. Estava com 103 quilos, fui para 88. (José)

Outro caso em que o trabalho intensificado levou a problemas de saúde é o de Lucas, que vivenciou um período de muita demanda, decorrente do elevado volume de trabalho, o que ocasionou problemas de tensão muscular que quase o impediam de andar:

Teve alguns meses, assim, de eu andar totalmente arqueado, como se eu estivesse realmente muito doente, e era questão muscular. Era nervo sendo comprimido pela própria musculatura, pela coluna, e aí o negócio vira uma bola de neve, fica muito dolorido, sabe? (Lucas)

Maurício, o mais novo dentre os entrevistados (27 anos), também relatou diversos problemas de saúde, aos quais ele atribuiu como causa o estresse originado no dia a dia de trabalho, que ele descreveu como intensificado tanto em termos de volume e ritmo de trabalho, quanto de extensão da jornada:

Já sofri com variação de peso, com queda de cabelo, com tremedeira, com gastrite, esofagite. Já tive uma série de problemas devido ao estresse .... Eu tive um princípio de úlcera, quase, no estômago, e o único motivo era o estresse. (Maurício)

Fábio relatou ter desenvolvido problemas de queda de cabelo (calvície precoce), desgaste generalizado e ansiedade, em decorrência do trabalho intensificado que vivenciou como gerente na área de transportes. Sobre a ansiedade, ele relatou: "Eu acho que essa ansiedade, eu adquiri no trabalho. Eu não era ansioso, porque daí tu está sempre preocupado em saber o que está acontecendo .... E é do trabalho. Isso é do trabalho" (Fábio).

A ansiedade, para Fábio, apresentava-se constantemente, mas ocorria, principalmente, nas situações em que o trabalho não estava conferindo os resultados esperados e as cobranças começavam a ocorrer. Para ele, a ansiedade apresentava-se também fora do ambiente de trabalho, devido à manutenção da preocupação com os resultados, e expressava-se na forma de dificuldades para dormir e também no corpo, como uma sensação de calor.

Os casos relatados ilustram alguns dos problemas de saúde que os entrevistados consideraram como decorrentes do trabalho gerencial, principalmente das condições laborais intensificadas. Em resumo, e considerando o relato de todos os entrevistados, identificamos os seguintes impactos do trabalho intensificado na saúde: problemas no 
estômago (gastrite, esofagite e úlcera); musculares (travamento de coluna e tensão muscular); cardiovasculares (pressão alta e taquicardia); obesidade e variações de peso (ganho de peso e emagrecimento); problemas capilares (queda, branqueamento e alopecia); estresse; ansiedade; dificuldades de concentração; redução da disposição; desgaste físico e mental, além do uso de álcool como forma de reduzir o estresse sentido no dia a dia. Os dados aqui encontrados acerca dos impactos do trabalho intensificado sobre a saúde estão em consonância com os estudos sobre o trabalho gerencial. Entre eles, podemos citar Nascimento, Duarte e Mendes (2012), que identificaram relatos de estresse, desgaste físico e mental entre gerentes de banco, e Máximo (2009), que apontou a ocorrência de problemas gastrintestinais (úlcera, gastrite, falta de apetite), colesterol alto, problemas na visão e dermatite, além dos sintomas psíquicos: nervosismo, irritabilidade, alterações do sono (insônia e pesadelos com o trabalho), depressão, tensão, estresse e dificuldade de concentração, também entre gerentes de banco. Não encontramos, entretanto, sintomas de LER/DORT (Lesão por Esforço Repetitivo/ Distúrbio Osteomuscular Relacionado ao Trabalho), que foram identificados nas pesquisas destes dois autores.

Tendo como referência a Medicina Social Latino Americana, podemos associar os problemas de saúde identificados pelos entrevistados às cargas presentes no contexto laboral expresso por eles. A carga psíquica, mais especificamente, a sobrecarga psíquica, entendida como decorrente de situações de tensão prolongada, pode ser considerada como predominante no contexto de trabalho dos gestores, já que eles relataram viver em um ambiente de muita tensão, em que, a qualquer momento, poderia surgir um problema que demandasse rápida resolução. Isso os levava a estar, permanentemente, alertas e atualizados sobre o que se passava nas unidades sob sua responsabilidade. Ademais, essa atenção não se restringia ao tempo em que estavam na empresa, mas era requerida também fora do local e horário de trabalho, o que fazia com que a carga fosse potencializada pela extensão das preocupações para outros ambientes. Os tipos de problemas de saúde que foram verificados por meio das entrevistas, no nosso entendimento, podem ser considerados como expressões das cargas psíquicas sobre o corpo, como os problemas musculares, digestivos, capilares e as manifestações de ansiedade. Outro tipo de carga que podemos considerar é a carga fisiológica, que consiste, segundo Laurell e Noriega (1989), 
em atividades que demandam um esforço do corpo do trabalhador. Entendemos que, apesar de realizarem um trabalho predominantemente intelectual, não podemos negligenciar a existência, também para os gestores, de atividades que levam ao desgaste físico, como o elevado ritmo de trabalho, o uso de computadores e as viagens, por exemplo. Temos que sopesar, ainda, que a demanda física amplia-se diante das longas jornadas, do trabalho em fins de semana e do pouco tempo para o repouso.

Para Laurell e Noriega (1989), o padrão de desgaste de um grupo de trabalhadores tem origem na maneira específica como se articulam a base técnica e a organização e divisão do trabalho, concepção compartilhada por Dal Rosso (2008), que considera que há um perfil patológico específico para trabalhadores de diferentes setores e tipos de atividades. O que podemos dizer a este respeito é que parece haver, realmente, a tendência de ocorrerem mais problemas de ordem psicológica e emocional entre os trabalhadores imateriais, como é o caso dos gestores, o que está de acordo com os resultados das pesquisas sobre consequências do trabalho intensificado para atividades imateriais encontradas na literatura.

\section{O trabalho e as demais esferas da vida}

A segunda categoria de consequências do trabalho intensificado refere-se à conciliação do tempo de trabalho com as demais esferas da vida. A existência de dificuldades de conciliação entre vida laboral e vida privada foi identificada em pesquisas com gerentes, dentre as quais, podemos destacar as de Almeida e Merlo (2008), Silva e Rosseto (2010) e Oltramari, Grisci e Weber (2011), que apontaram a existência de queixas sobre a elevada jornada de trabalho, a disponibilidade necessária fora do horário normal e as atividades que levavam para casa como fatores intervenientes na conciliação entre trabalho e família.

Os relatos dos gestores entrevistados na presente pesquisa acerca das dificuldades de conciliação trabalho-família foram bastante claros e estiveram presentes em todas as entrevistas. Por outro lado, essas dificuldades de conciliar trabalho e família foram apresentadas, muitas vezes, como algo normal, natural e inerente à função deles. Um relato 
que retrata bem as dificuldades de conciliação entre as demandas de um trabalho intensificado e a esfera familiar é o de Victor, que expressou como a jornada elevada, o cansaço decorrente da rotina de trabalho e a invasão deste no ambiente familiar por meio das tecnologias de comunicação Ihe traziam dificuldades. Por outro lado, o relato também revelou a adaptação da família às suas condições de trabalho:

Atrapalha muito esse negócio de logística. Minha esposa, no começo, ela não entendia muito, era muito difícil, tá? Agora ela acaba compreendendo e aceitando muito mais. Entende a minha posição dentro da empresa, sabe que eu não bato cartão, sabe que é bem difícil de gerenciar. Ela sabe que muitas das vezes eu chego em casa e eu não consigo é... por mais que eu queira, mas eu não consigo dar atenção, porque o telefone toca, ou é no WhatsApp, tem que responder, isso, aquilo, mas no todo é bem difícil de conciliar, ainda mais quando você tem filho .... Então, não é fácil, não é fácil, quando o corpo está pedindo para dormir, para descansar, você tem ainda todo aquele papel de pai e tudo mais. (Victor)

Ainda, no âmbito familiar, cabe mencionar que muitos dos entrevistados mudaramse diversas vezes de cidade, em razão de trocas de emprego ou de transferências. As mudanças, na perspectiva dos entrevistados, levavam às dificuldades para criar raízes, para se adaptar e para estabelecer vínculos. É sempre necessário fazer novas amizades, adaptarse a novas cidades, casas, escolas, funções etc., o que nos remete às características do capitalismo contemporâneo, apontadas por Sennett $(2006,2009)$, como as relações de curto prazo, as constantes migrações e a necessidade de desapego do passado e das vivências que, não sem razão, provocam sofrimento. As constantes migrações, ainda, criaram dificuldades para as esposas trabalharem e consolidarem suas carreiras, o que está em consonância com o estudo de Brett e Stroh (2003), que apontou que 99\% dos gerentes que trabalhavam por mais de 60 horas semanais tinham esposas que não estavam empregadas e, portanto, conferiam o suporte familiar necessário para o engajamento deles em longas jornadas. Essa questão também nos remete à persistência dos papéis de gênero e à menor valorização da carreira feminina. 


\section{A diluição das fronteiras entre tempos de trabalho e não-trabalho}

Dando sequência à descrição das consequências do trabalho intensificado na vida dos gestores, temos a permanência das preocupações com o trabalho para além do local e horário onde deveriam ocorrer. Não podemos dizer que a continuidade dessas preocupações é exclusividade de quem tem um trabalho intensificado, mas consideramos que este potencializa as preocupações, tanto pela permanência da responsabilidade por operações que ocorrem 24 horas por dia, como é o caso dos gestores entrevistados, quanto pela preocupação com os resultados, diante de uma gestão baseada em metas. Durante as entrevistas, diversos entrevistados relataram que passavam parte do seu tempo livre pensando no trabalho, nas metas a serem alcançadas e nas pendências a serem resolvidas, principalmente quando passavam por períodos de resultados ruins ou de maior intensidade laboral, em que havia mais demandas do que eles conseguiam resolver durante a jornada de trabalho. Os relatos dos entrevistados podem ser, resumidamente, ilustrados por expressões como:

[Você] vira frango assado de padaria na cama, pensando nas coisas. (José)

Às vezes eu acordo às $4 \mathrm{~h}$ da manhã, às $5 \mathrm{~h}$ da manhã, dependendo do período do mês, e fico pensando: será que vamos conseguir entregar o que a gente está combinando? (Fábio)

Eu já cheguei a dormir, em algumas épocas, com um caderno do lado, para anotar algumas coisas que eu pensava para não esquecer depois. (Henrique)

A permanência das preocupações, portanto, consumiam um tempo que poderia ser dedicado a outras atividades e, muitas vezes, expressava-se em insônia, um distúrbio que pode desencadear outros problemas de saúde. Por tudo que foi relatado pelos entrevistados, parece não haver mais a distinção entre os tempos e locais de trabalho e não-trabalho. A invasão do trabalho na vida privada, segundo Mansano (2009), é facilitada pelo fato de o trabalho imaterial não depender, exclusivamente, dos meios de produção do empregador, mas também e, principalmente, da inteligência, da comunicação, da criação e da cooperação dos trabalhadores, que pode ser obtida em qualquer local e tempo, especialmente diante das facilidades promovidas pelas tecnologias de comunicação e informação. 
"Eu prefiro trabalhar num trabalho intenso do que em um trabalho que seja morno": a relação paradoxal com o trabalho intensificado

Apesar das consequências negativas do trabalho intensificado na vida dos gestores entrevistados, encontramos elementos que sugerem a existência de compensações decorrentes da aceitação das condições de trabalho intensificadas, muito embora todas elas tenham que ser ponderadas. Um ponto que pode ser levantado acerca do "benefício" de um trabalho intensificado refere-se à recorrente menção dos gestores sobre gostar do ritmo de trabalho, embora não apreciem a sua extensão. Esse gosto se expressa em frases, como:

Basicamente, eu gosto do dia nervoso mesmo, quando tem muita coisa acontecendo ao mesmo tempo. (Jefferson)

Eu prefiro trabalhar num trabalho intenso do que em um trabalho que seja morno. (Marcos)

Os entrevistados apontaram gostar de ter um trabalho que eles consideram dinâmico, que não os deixa parados, que faz o tempo passar rápido e que também os faz sentirem-se produtivos pela grande quantidade de atividades realizadas durante o dia. Parece que o trabalho intensificado agrada os entrevistados pela sensação de redução da monotonia e também, ou talvez, principalmente, pela sensação de ser produtivo e de rentabilizar o tempo. Isso nos remete à ideologia gerencialista, que, de acordo com Gaulejac (2007), leva os trabalhadores a incorporarem a necessidade de dar provas do seu valor, da sua produtividade e da sua contribuição para a empresa, no sentido de construir "um tempo integralmente rentável" (p. 101). Para esse autor, práticas, discursos e técnicas são empregados com a finalidade de obter a adesão dos trabalhadores às exigências da empresa e dos acionistas, o que faz do gerenciamento uma tecnologia de poder do capital sobre o trabalho. Como o gerencialismo se apresenta como pragmático e racional, os seus instrumentos não são contestados, ainda mais porque se associam a valores "positivos", como o gosto do empreender, o desejo de progredir, a celebração do mérito e o culto da qualidade, que são valores que vão ao encontro das aspirações humanas e, portanto, auxiliam na adesão à ideologia gerencialista. Assim, a incorporação desse modo de pensar a prática profissional dos gestores os leva a valorizar a produtividade e a rentabilidade e, em 
decorrência, pode fazer com que as condições de trabalho, que deveriam ser questionadas, passem a ser suportadas, aceitas e, até mesmo, percebidas como satisfatórias.

Além do gosto pelo ritmo, pudemos constatar a existência de benefícios financeiros decorrentes da aceitação de condições de trabalho intensificadas. Na percepção dos entrevistados, não são todas as pessoas que suportam ou têm o perfil para trabalhar sob condições intensificadas e, portanto, aqueles que as aceitam recebem melhores remunerações e bonificações, bem como são reconhecidos, promovidos e conseguem crescer profissionalmente. Alguns deles relataram ter feito escolhas de carreira que evidenciam terem colocado em segundo plano as dificuldades de um trabalho mais intensificado em razão do crescimento profissional e da melhor remuneração que este poderia proporcionar. Essa escolha pode ser observada no relato de Maurício, que optou por mudar para uma área da empresa em que o trabalho era mais intensificado, visando o crescimento profissional em detrimento da qualidade de vida que considerava ter anteriormente: "Minha qualidade de vida era muito melhor na [área] comercial. Eu optei por voltar para a operação justamente para ter, para galgar esse crescimento, e que veio, realmente" (Maurício).

Entendemos, portanto, que houve, no caso de Maurício e também de outros entrevistados, uma opção por migrar para um trabalho mais intensificado, que foi compensada por fatores como progressão na carreira, melhoria de salário e novos desafios. Não podemos, entretanto, dizer que se trata de uma escolha totalmente livre, pois parece não haver, na opinião dos entrevistados, muitas opções para crescer profissionalmente sem que isso implique em um aumento na intensidade do trabalho, especialmente no setor de logística de transportes. Por isso, recursar a intensificação pode implicar em deixar de progredir na carreira, perder o emprego ou ter que mudar de ramo de atividade. A necessidade de aceitar a intensificação do trabalho para progredir profissionalmente é reforçada por concepções, tais como: para crescer e se manter na área de logística, tem que estar disposto ao trabalho árduo e a manter-se disponível 24 horas para a empresa. 0 trecho a seguir ilustra essa concepção que foi compartilhada entre os gestores entrevistados: "Quem não se adéqua a essa rotina acaba que tem que procurar um outro modelo, trabalhar em outra área que não seja de transporte, que não seja logística" 
(Maurício).

Por meio das entrevistas, pudemos perceber que a disponibilidade 24 horas por dia, um elemento crucial na intensificação do trabalho dos gestores, é vista como exigência na área de logística de transportes, tendo, até mesmo, se naturalizado. Essa disponibilidade para o trabalho apareceu como um valor importante, principalmente porque os entrevistados falaram da existência de uma imagem positiva e da valorização que recebiam por parte da família devido à dedicação ao trabalho. Por outro lado, os gestores entrevistados também vincularam o trabalho intensificado à loucura, principalmente ao relatarem o que outras pessoas pensam sobre suas condições laborais. De forma implícita, eles também consideravam as suas condições de trabalho como algo anormal, mas em nenhum momento das entrevistas expressaram formas de contestação, de revolta ou de necessidade ou vontade de mudar e lutar contra tais condições. Podemos considerar que a amenização da precariedade das condições laborais pode estar relacionada, além de com benefícios citados anteriormente, com a posição hierárquica ocupada, no sentido de que é inadequado um gerente demonstrar insatisfação com a empresa e com seu trabalho. No entanto, acreditamos mais fortemente que isso decorra da não percepção de que essas condições vivenciadas deveriam levar à insatisfação, à revolta e à ação. A forma de trabalhar e as exigências do trabalho estão naturalizadas para os gestores, o que pode advir da adesão à ideologia gerencial, como apontamos previamente.

Ademais, levando em consideração as contribuições de Pagès et al. (2006), entendemos que as organizações possibilitam satisfações de diversas ordens que, de certo modo, levam em conta o que está no ideário social sobre qual é a função do trabalho nas nossas vidas. As políticas de caráter ideológico empregadas pelas organizações vêm mediar os conflitos e atitudes ambivalentes em relação ao trabalho e à organização. Se, por um lado, há restrições e imposições, por outro, há vantagens que integram o indivíduo à organização e o fazem aceitar a exploração e a dominação da empresa. Encontramos, nas entrevistas, referências a todos os tipos de satisfação que as organizações poderiam oferecer e que foram apontadas por Pagès et al. (2006), como a existência de um trabalho interessante, com responsabilidades e desafios, que permite conquistas de diversas ordens, possibilidade de carreira, de poder, altos salários e bonificações, além de satisfações morais, 
como a contribuição para a empresa, a produção de um legado e a colaboração para o desenvolvimento dos outros.

Observamos, portanto, que as consequências do trabalho gerencial intensificado são paradoxais. Se, por um lado, há insatisfações, especialmente em relação à invasão do trabalho na vida privada, há também satisfações oriundas de um trabalho que não é monótono, que confere a sensação de produtividade e promove um padrão de vida que a maior parte dos trabalhadores não consegue obter. Há um preço a pagar: saúde, família, descanso e tempo estão prejudicados, mas parecem ser compensados pelas gratificações oriundas do trabalho, em especial o reconhecimento, a remuneração e as possibilidades de crescimento profissional.

\section{Considerações finais}

Os resultados da pesquisa realizada nos levaram a identificar a ocorrência de consequências que podem ser consideradas negativas para os gestores que vivenciam o trabalho intensificado, que se referem aos problemas de saúde, dificuldades de conciliação entre trabalho e vida privada e diluição das fronteiras entre essas duas esferas, que conduz à invasão das demandas e das preocupações com o trabalho em locais e espaços onde não deveriam ocorrer. Embora a extensão da jornada (presencialmente ou não), que é uma das características do trabalho intensificado, tenha se revelado como motivo de incômodo para os entrevistados, a outra característica, que se refere ao ritmo elevado, não se mostrou como motivo de reclamação por parte dos gestores. Isso parece estar associado à incorporação do gerencialismo, que prega o gosto pela produtividade, pela rentabilização e pelo não desperdício do tempo, além de ser fruto das políticas das organizações, que por meio das satisfações oferecidas, antecipam-se e evitam o surgimento dos conflitos. Ademais, o trabalho intensificado é considerado pelos gestores como capaz de prover melhores condições de carreira e de vida para aqueles que conseguem suportá-lo ou até mesmo apreciá-lo. Desse modo, as consequências são paradoxais, pois, apesar dos malefícios que o trabalho intensificado pode trazer para os gestores e também para seus familiares, ele traz gratificações, principalmente em termos financeiros e de realização 
profissional.

Consideramos que as condições de trabalho vivenciadas pelos gestores relacionamse aos efeitos das modificações na organização do trabalho a partir da década de 1970, como as novas ferramentas de gestão utilizadas pelas empresas, especialmente a gestão por metas, e as tecnologias de comunicação e informação, que eliminam as restrições de tempo e espaço para o trabalho imaterial. Mas é preciso entender que não basta a existência da tecnologia, é necessário ter um trabalhador que esteja disposto a utilizá-la. Para tanto, ele deve incorporar essa necessidade de estar disponível e de rentabilizar todo o seu tempo de trabalho, considerando esta uma condição desejável e natural. Nesse sentido, a ideologia gerencial e suas tecnologias de gestão encaixam-se como uma luva nos contextos de trabalho ao disseminarem a necessidade de um trabalhador integralmente disponível, acessível e rentável. Ademais, as condições do mercado de trabalho apontadas pelos gestores, que identificam que não há opções de trabalho não intensificados, além do medo de atender às exigências da empresa, fracassar e perder o emprego, devem ser consideradas para a compreensão do cenário em que os gestores estão inseridos.

Acreditamos que a abordagem do trabalho intensificado no setor de logística de transportes foi bastante frutífera, pois encontramos condições de trabalho extremamente intensificadas, especialmente em relação à onipresença do trabalho, ou seja, a (quase completa) inexistência de tempos de não trabalho decorrente, principalmente, da ininterrupção das operações, elementos da organização do trabalho nesse setor que, portanto, favorecem a intensificação laboral.

Novas pesquisas sobre esse tema poderiam ser enriquecidas por meio do acesso ao local de trabalho e da realização de entrevistas com a família de gestores, com a adoção de outras perspectivas teóricas e recortes (geracionais e de gênero, por exemplo), além da realização de estudos comparativos com trabalhadores de diferentes setores econômicos, países ou regiões geográficas.

\section{Referências}

Almeida, L. L., \& Merlo, A. R. C. (2008). Manda quem pode, obedece quem tem juízo: prazer e sofrimento psíquico em cargos de gerência. Cadernos de Psicologia Social do 
Trabalho, 1 1(2), 139-157. http://pepsic.bvsalud.org/pdf/cpst/v1 ln2/a02v1 ln2.pdf Borges, A. P., \& Joia, L. A. (2013). Executivos e smartphones: uma relação ambígua e paradoxal. Organização \& Sociedade, 20(67), 585-602. http://dx.doi.org/10.1590/S1 984-92302013000400002

Brasil, República Federativa do Brasil. Ministério da Saúde. (2012). Resolução $n^{\circ} 466$ de 12 de dezembro de 2012. Dispõem diretrizes e normas regulamentadoras de pesquisas envolvendo seres humanos. Brasília, DF: Ministério da Saúde. http://bvsms.saude.gov.br/bvs/saudelegis/cns/2013/res0466_12_12_2012.html

Brett, J. M., \& Stroh, L. K. (2003). Working 61 plus hours a week: why do managers do it? Journal of Applied Psychology, 88(1), 67-78. https://doi.org/10.1037/00219010.88 .1 .67

Burke, R. J., \& Fiksenbaun, L. (2008). Work hours, work intensity, and work addiction: costs and benefits. In R. J. Burke, \& C. L. Cooper (Eds.), The long work hours culture: causes, consequences and choices (pp. 3-36). United Kingdon: Emerald.

Cavazotte, F. S. N., Lemos, A. H. C., \& Brollo, M. S. (2014). Trabalhando melhor ou trabalhando mais?: um estudo sobre usuários de smartphones corporativos. Organizações \& Sociedade, 21(68), 769-788. http://dx.doi.org/10.1590/S198492302014000100002

Dal Rosso, S. (2006). Intensidade e imaterialidade do trabalho e saúde. Trabalho, Educação e Saúde, 4(1), 65-91. http://dx.doi.org/10.1590/S1981-77462006000100005

Dal Rosso, S. (2008). Mais trabalho!: a intensificação do labor na sociedade contemporânea. São Paulo: Boitempo.

Davel, E., \& Melo, M. C. O. L. (2005). Singularidades e transformações no trabalho dos gerentes. In E. Davel \& M. C. O. L. Melo (Orgs.), Gerência em ação: singularidades e dilemas do trabalho gerencial (pp. 29-65). Rio de Janeiro: Editora FGV.

Deslandes, S. F. (2009). O projeto de pesquisa como exercício científico e artesanato intelectual. In M. C. S. Minayo (Org.), Pesquisa Social: teoria, método e criatividade (28a ed., pp. 31-60). Petrópolis: Vozes.

Fleury, P. F., Wanke, P., \& Figueiredo, K. F. (2000). Logística Empresarial: a perspectiva brasileira. São Paulo: Atlas. 
Gaulejac, V. (2007). Gestão como doença social: ideologia, poder gerencialista e fragmentação social (2a ed., I. Storniolo, Trad.). Aparecida: Ideias e Letras. (Coleção Management, v. 4)

Gomes, R. (2009). Análise e interpretação de dados de pesquisa qualitativa. In M. C. S. Minayo (Org.), Pesquisa social: teoria, método e criatividade (28a ed., pp. 79-108). Petrópolis: Vozes.

Green, F. (2004). Why has work effort become more intense? Industrial Relations, 43(4), 709-741. http://onlinelibrary.wiley.com/doi/10.1111/j.0019-8676.2004.00359.x/ abstract

Grisci, C. L. I. (2011). Trabalho imaterial. In A. D. Cattani \& L. Holzmann (Orgs.), Dicionário de trabalho e tecnologia (2a ed., rev. e ampl., pp. 456-458). Porto Alegre: Zouk.

Hardt, M., \& Negri, A. (2001). Império. (2a. ed., Vargas, B., Trad.). Rio de Janeiro: Record.

Laurell, A. C., \& Noriega, M. (1989). Processo de produção e saúde: trabalho e desgaste operário (A. Cohn, A. Pitta-Hoisel, A. I. Paraguay, \& L. H. Barbosa, Trads.). São Paulo: Hucitec.

Leite, L. T. T., \& Paiva, K. C. M. (2009). Gestão e subjetividade: a fala dos gerentes (re)velando aspectos da função gerencial contemporânea. Revista Gestão \& Tecnologia, 9(2), 1-19. https://doi.org/10.20397/2177-6652/2009.v9i2.244

Lemos, A. H. C., Gottlieb, L. S. N., \& Costa, A. S. M. (2016). Pressure, performance and prestige: dilemmas for contemporary professionals. Organização \& Sociedade, 23(79), 539-552. https://doi.org/10.1590/1984-9230791

Lima, C. A., Barros, E. M. C., \& Aquino, C. A. B. (2012). Flexibilização e intensificação laboral: manifestações da precarização do trabalho e suas consequências para o trabalhador. Labor, 1(7), 102-125. https://doi.org/10.29148/labor.v1i7.6708

Mansano, S. R. V. (2009). Transformações da subjetividade no exercício do trabalho imaterial. Estudos e Pesquisas em Psicologia, 9(2), 512-524. www.epublicacoes.uerj.br/index.php/revispsi/article/view/9120/6996

Máximo, T. A. C. O. (2009). Super-homem moderno: a análise da relação trabalho-saúde de gerentes de bancos públicos e privados [Dissertação de Mestrado, Universidade Federal da Paraíba]. Repositório Institucional da UFPB. 
http://tede.biblioteca.ufpb.br/handle/tede/6942

Máximo, T. A. C. O., Araújo, A. J. S., \& Zambroni-de-Souza, P. C. (2014). Vivências de sofrimento e prazer no trabalho de gerentes de banco. Psicologia: Ciência e Profissão, 34(1), 96-111. https://doi.org/10.1590/S1414-98932014000100008

Nascimento, M. M. R., Duarte, F. S., \& Mendes, A. M. (2012). Implicações do trabalho bancário de suporte e atendimento nas vivências de sofrimento dos trabalhadores. Revista AMAzônica, 5(2), 162-189. https://dialnet.unirioja.es/servlet/articulo? codigo $=4047140$

Navarro, V. L., \& Padilha, V. (2007). Dilemas do trabalho no capitalismo contemporâneo. Psicologia \& Sociedade, 19(1), 14-20. http://doi.org/10.1590/S010271822007000400004

Neves, D. R., Lemos, A. H. C., \& Costa, A. S. M. (2014). Contrato psicológico em empresas de alta performance: a dor e a delícia de ser um trabalhador contemporâneo. Sociedade, $\begin{array}{lllll}\text { Contabilidade } & \text { e } & \text { Gestão, } & \text { 9(2), }\end{array}$ http://www.atena.org.br/revista/ojs-2.2.3-06/index.php/ufrj/article/view/2257

Oltramari, A. P., Grisci, C. L. I., \& Weber, L. (2011). Carreira e relações familiares: dilemas de executivos bancários. Revista Mal Estar e Subjetividade, 11(1), 101-133. http://pepsic.bvsalud.org/scielo.php?script=sci_arttext\&pid=S151861482011000100005

Pajès, M., Bonetti, M., Gaulejac, V., \& Descendre, D. (2006). O poder das organizações (M. C. P. Tavares \& S. P. Favatti, Trads.). São Paulo: Atlas.

Pina, J. A. (2012). Intensificação do trabalho e saúde dos trabalhadores na indústria automobilística: estudo de caso na Mercedes Benz do Brasil [Tese de Doutorado, Escola Nacional de Saúde Pública Sergio Arouca]. Repositório Institucional da Fiocruz. https://www.arca.fiocruz.br/handle/icict/ 14457

Scanfone, L., Carvalho Neto, A., \& Tanure, B. (2008). Tempos de trabalho e de não-trabalho: o difícil equilíbrio do alto executivo entre a carreira, as relações afetivas e o lazer. Revista de Administração FACES Journal, 7(1), 45-61. http://doi.org/10.21714/19846975FACES2008V7N1ART109

Sennett, R. (2006). A cultura do novo capitalismo (C. Marques, Trad.). Rio de Janeiro: Record. 
Sennett, R. (2009). A corrosão do caráter: as consequências pessoais do trabalho no novo capitalismo (14a ed., M. Santarrita, Trad.). Rio de Janeiro: Record.

Silva, A. B., \& Rosseto, C. R. (2010). Os conflitos entre a prática gerencial e as relações em família: uma abordagem complexa e multidimensional. Revista de Administração Contemporânea, 14(1), 40-60. http://doi.org/10.1590/S1415-65552010000100004

Vinuto, J. (2014). A amostragem em bola de neve na pesquisa qualitativa: um debate em aberto. Temáticas, 22(44), 203-220. https://doi.org/10.20396/tematicas.v22i44.10977

\section{Notas de fim}

\footnotetext{
' O termo gestores será utilizado para se referir a ocupantes de cargos de gestão, como coordenadores e gerentes. Para designar o trabalho realizado pelos gestores, será utilizada a expressão trabalho gerencial.

ii Pesquisa realizada em março de 2019, nos portais Scielo e Pepsic. Para "gerente" e "gerência", no período 2014 a 2019, foi encontrada apenas uma referência que abordava as condições de trabalho dos gerentes em específico (Máximo, Araújo, \& Zambroni-de-Souza, 2014). Para os termos "intensificação do trabalho", "intensificação laboral" e "trabalho intensificado", foram identificados, após leitura dos resumos, 27 artigos empíricos. Destes, 16 abordavam a intensificação laboral de docentes em instituições públicas, sete foram realizados com trabalhadores em atividades manuais, um com assistentes em administração e apenas três incluíam, entre os trabalhadores, profissionais em cargos de gestão (Cavazotte, Lemos, \& Brollo, 2014; Lemos, Gottlieb, \& Costa, 2016; Máximo, Araújo, \& Zambroni-de-Souza, 2014). O presente estudo tem como foco trabalhadores em funções imateriais do setor privado, duas características que os distinguem daqueles mais frequentemente estudados na literatura sobre intensificação do trabalho.

iii Pesquisa realizada em março de 2019, nos portais Scielo e Pepsic, com os termos: "logística" e "transporte", isoladamente, bem como associados aos termos "gestor", "gerente", "trabalho gerencial" e "função gerencial". Três pesquisas empíricas foram realizadas com trabalhadores do setor de transportes, mas envolveram motoristas de caminhão e cobradores e motoristas de ônibus urbanos.

iv Os nomes são fictícios.
}

Recebido em: 20/8/2018

Aprovado em: 4/4/2019 